\title{
MELIHAT KESEIMBANGAN VISUAL DALAM TIPOGRAFI (STUDI KASUS KARYA DESAIN LOGOTYPE PADA MATA KULIAH TIPOGRAFI DASAR)
}

\author{
Brian Alvin Hananto ${ }^{1^{*}}$ \\ ${ }^{1}$ Program Studi Desain Komunikasi Visual, Universitas Pelita Harapan, Tangerang \\ Diterima: 7 Agustus 2018/ Disetujui: 12 Oktober 2018
}

\begin{abstract}
The issue on visual balance in design is something that is often mentioned but perhaps not discussed or studied thoroughly nowadays. The skeptical view on visual balance may have derived from thoughts that visual balance is something simple, that it can be easily achieved without any concerns. Another popular yet misleading view is that visual balance is something personal and subjective, where anyone has their own 'tastes' and personal reasons on how a design is balanced or not and they don't need to describe or provide any rationale reasons behind their remarks. This article discusses an excercise that resulted in five logotype designs that were made from Foundational Typography class from the Visual Communication Design department on Universitas Pelita Harapan. The focus of the discussion is on explaining how these five designs has reached visual balance and how these five designs achieved so without sacrificing their purpose as a readable logotype. Therefore, this writing hopes to provide references and explanations on how a logotype can achieve visual balance from typography.
\end{abstract}

Keywords : Typography, Visual Balance, Logotype

\begin{abstract}
ABSTRAK
Isu seputar keseimbangan visual dalam desain adalah hal yang seringkali disebut namun mungkin tidak banyak dibahas atau dipelajari dewasa ini. Hal ini terjadi karena masih adanya pandangan bahwa keseimbangan visual adalah suatu hal yang sederhana, yang dapat dicapai dengan mudah dan tanpa pertimbangan yang macam-macam. Selain sederhana, keseimbangan juga kerap dianggap sebagai hal yang sifatnya subyektif, dimana setiap orang memiliki opini tersendiri mengenai apakah sebuah desain itu seimbang atau tidak dan orang tersebut tidak perlu memberikan landasan atau argumentasi mengenai hal tersebut. Tulisan ini membahas sebuah latihan yang menghasilkan lima rancangan logotype yang dihasilkan dalam mata kuliah Tipografi Dasar dalam program studi Desain Komunikasi Visual di Universitas Pelita Harapan. Fokus utama pembahasan rancangan-rancangan tersebut adalah mengenai bagaimana kelima desain tersebut mencapai keseimbangan visual dan bagaimana kelima desain tersebut memperolehnya tanpa mengesampingkan fungsinya sebagai sebuah logotype yang dapat dibaca. Dengan demikian, tulisan ini berharap untuk dapat menjadi referensi bagaimana keseimbangan visual dapat dicapai secara obyektif melalui tipografi.
\end{abstract}

Kata Kunci : Tipografi, Keseimbangan Visual, Logotype

\section{PENDAHULUAN}

Dewasa ini, berkomunikasi secara visual tentu sulit untuk melepaskan diri dari penggunaan huruf. Paradigma sederhana inilah yang menjadi dasar mengapa mata kuliah tipografi dasar disajikan di tahun pertama perkuliahan di program studi Desain
Komunikasi Visual di Universitas Pelita Harapan. Program studi yang memiliki tiga peminatan (animasi, desain grafis, dan sinematografi) ini mengajarkan bahwa tulisan adalah sebuah sarana komunikasi visual yang perlu dimengerti karena akan digunakan dalam ketiga peminatan tersebut dalam berbagai kebutuhannya. Hasilnya

*email: brian.hananto@uph.edu 
adalah mata kuliah dasar yang menitikberatkan mengenai membentuk dan menata huruf dalam berbagai objek desain.

Perkuliahan di mata kuliah ini pun berlangsung dalam format seperti mata kuliah studio, dimana pelaksanaan perkuliahan banyak dihabiskan untuk membuat karya di dalam kelas dan mendiskusikan hasil pekerjaan mahasiswa di kelas. Pembahasan dapat dilakukan secara individual, dalam kelompok, maupun pin up didalam kelas. Hal ini dilakukan karena permasalahan dalam karya tipografi sering kali beragam, namun secara prinsip sebenarnya serupa.

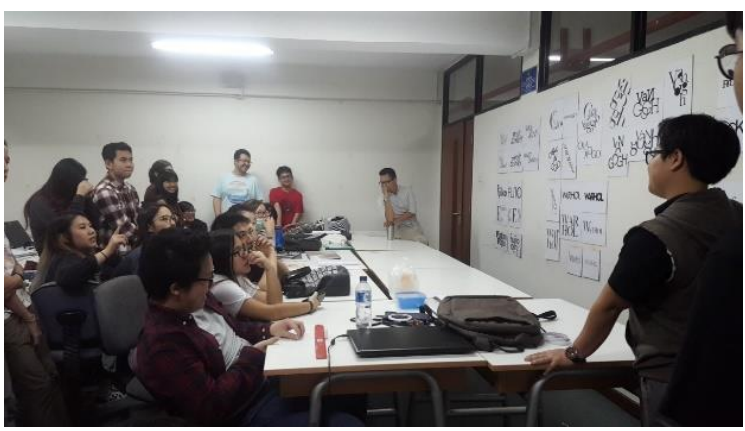

Gambar 1 Kegiatan Pin Up pada

Perkuliahan Tipografi Dasar DKV UPH (Sumber: Hananto, 2018)

Mahasiswa didorong untuk menganalisa karya teman-temannya didalam kelas sebagai bentuk pembelajaran. Diskusi dalam kelas yang dimoderasi oleh dosen biasanya mengundang diskusi antar mahasiswa bukan hanya dalam tatanan formil karya, namun juga pada gagasan-gagasan mahasiswa yang melatari pembuatan karya. Pertanyaan-pertanyaan seputar "mengapa melakukan ini dan bukan melakukan itu?" menjadi sesuatu yang tidak asing dalam perkuliahan Tipografi Dasar, khususnya pada latihan-latihan yang sifatnya pemecahan masalah dalam aspek tipografi. Karena seperti yang diketahui, ada banyak cara dalam menyelesaikan sebuah permasalahan visual.

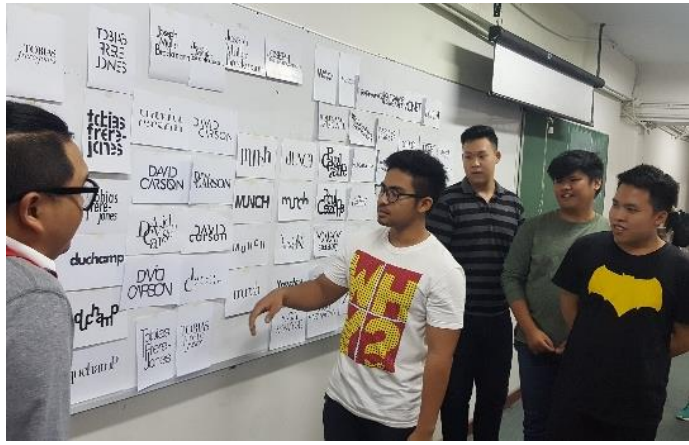

Gambar 2 Pembahasan Karya yang dilakukan Mahasiswa pada Perkuliahan Tipografi Dasar DKV UPH

(Sumber: Hananto, 2018)

Pada Gambar 2, mahasiswa yang sedang membahas latihan desain logotype yang merupakan latihan mendesan kedua dalam mata kuliah ini. Latihan sebelumnya adalah latihan mendesain monogram, yang hanya menggunakan dua atau tiga huruf, sedangkan latihan logotype sendiri merupakan latihan lanjut, dimana jumlah huruf yang digunakan sudah membentuk sebuah kata, dan kata tersebut perlu dibaca. Logotype sendiri adalah salah satu kategori logo yang juga sering disebut sebagai woodmark, dimana sang logo menampilkan nama perusahaan atau produk dengan tipografi yang unik (Landa, 2011: 247).

Brief latihan logotype ini adalah untuk mendesain sebuah logotype dimana nama perusahaan atau entitas yang diangkat adalah nama orang-orang terkenal dalam lingkup DKV. Subjek) yang diangkat tidak perlu dikaitkan dengan visual desain; karena dalam latihan ini, diharapkan memfokuskan mahasiswa dapat mendesain dengan eksplorasi form dalam menyelesaikan permasalahan-permasalahan desain, dan bukan menggunakan 'konsep' sebagai argumen dalam eksplorasi form yang sifatnya mungkin prematur. Permasalahan desain yang perlu diselesaikan dalam latihan ini adalah isu mengenai balance, readability dan juga keunikan, karena yang dirancang adalah sebuah logo. Namun walaupun demikian, aspekaspek praktis dalam merancang logo (seperti logo harus terlihat dalam ukuran kecil) tidak menjadi faktor dalam penilaian. 
Tulisan ini memberikan penjelasan terhadap beberapa materi dan konsep dalam tipografi yang diajarkan dalam kelas. Selain membahas materi, tulisan ini juga membahas beberapa karya mahasiswa terpilih yang dihasilkan dalam kelas ini sebagai sampel Tujuan dari pemaparan ini adalah untuk membahas mengenai bagaimana para mahasiswa atau 'pemula' dalam tipografi ini mencoba menyelesaikan isu seputar balance dalam mendesain sebuah logotype dengan menggunakan beberapa hasil karya mahasiswa Desain Komunikasi Visual Universitas Pelita Harapan.

\section{TINJAUAN TEORI}

Definisi mengenai tipografi yang digunakan dalam perkuliahan adalah sebuah ilmu yang mempelajari mengenai bentuk huruf dan penyusunannya dalam dua dimensi dan pada dimensi ruang dan waktu (Landa, 2011:44). Pemaparan ini menunjukkan dua hal dalam tipografi, yaitu materi yang diolah (huruf) dan juga aplikasi dari pengolahan materi tersebut (dua dimensi dan dimensi ruang dan waktu). Penjelasan lain yang sering digunakan dalam mengilustrasikan tipografi adalah seni mekanistik dalam memproduksi huruf, angka, simbol, bentuk dalam pemahaman elemen, prinsip dan atribut desain (Solomon, 1994:8). Definisi yang lebih luas dari tipografi ini menggunakan istilah mekanistik karena memang pada awalnya tipografi adalah sebuah keahlian utama untuk para desainer dan para pencetak. Walau kental dengan paradigma 'lama', namun konsep tipografi dari Solomon ini tetap menjadi hal yang menarik dengan disinggungnya mengenai elemen, prinsip dan atribut desain. Solomon menegaskan bahwa tipografi adalah desain, sehingga keahlian dalam mendesain mengandaikan penguasaan tipografi dan dibutuhkan pemahaman desain yang komprehensif untuk dapat meguasai tipografi.

Salah satu atribut desain yang dibahas Solomon adalah balance. Keseimbangan, menurut Solomon, terbentuk ketika satu atau dua elemen secara visual mengimbangi satu sama yang lain (Solomon, 1994:44). Elemen visual dalam tipografi tentunya adalah elemen huruf. Dalam tipografi, penyusunan huruf-huruf ini untuk mengejar balance adalah sebuah hal yang fundamental, dan untuk mencapainya ada beberapa pertimbangan yang perlu diperhatikan. Mengingat bahwa huruf memiliki bentuk yang berbeda, maka untuk mengimbangi dua huruf yang berbeda (seperti ' $I$ ' dan ' $K$ ') tentu rumit, namun sebenarnya hal tersebut tidaklah sulit. Hal itu dikarenakan bentuk huruf yang didesain dengan baik pasti akan didesain agar setiap hurufnya sendiri sudah balance, dan pengaturan agar dua huruf tersebut bisa seimbang, yang perlu dilakukan adalah memperhatikan jarak antara huruf, kata ataupun baris kalimat (Bringhurst, 2004: 25).

Terdapat banyak cara atau metode untuk mencapai keseimbangan dalam desain $\&$ tipografi. Keseimbangan dari bentuk-bentuk variatif ini memerlukan pertimbangan antara jarak yang konsisten terhadap ritme elemen-elemen huruf tersebut, dan untuk mencapai hal tersebut, penyusunan antara baris kalimat perlu disusun sehingga tidak terlalu berjauhan namun tidak sampai bersentuhan antara baris tersebut (Jury, 2004:82). Setelah mengatur jarak antar baris, jarak antar kata dan huruf barulah diatur sedemikian rupa. Terdapat beberapa istilah mendasar ketika berbicara mengenai pengaturan jarak dalam tipografi. Istilahistilah tersebut terkadang suka memiliki pemahaman yang berbeda-beda, dengan demikian penulis akan memaparkan istilahistilah yang akan digunakan dalam pembahasan selanjutnya. Istilah-istilah yang digunakan adalah:

- Jarak vertikal konsisten antar baris kalimat disebut sebagai leading (Sihombing, 2001: 24). Patokan dari leading sebenarnya adalah baseline dari baris kalimat tersebut, dimana baseline adalah garis maya horisontal dimana huruf-huruf tersebut berdiri. 
- Jarak horisontal antar kata disebut sebagai word spacing (Sihombing, 2001:24)

- Jarak horisontal konsisten antara semua huruf secara keseluruhan disebut sebagai tracking (Lupton, 2004:81)

- Jarak horisontal spesifik antara dua huruf disebut sebagai kerning (Lupton, 2004:80)

Istilah-istilah jarak ini menjadi krusial karena mampu menyederhanakan pemahaman kompleks mengenai ruang-ruang yang luas dalam tipografi. Di kelas ketika ada tim dosen mengungkapkan permasalahan desan terletak pada leading, mahasiswa langsung mengetahui titik permasalahannya. Mahasiswa tersebut tidak akan melihat jarak antar kata atau jarak antar huruf namun langsung menyimak jarak antara baris kalimat. Ketika dikelas disebutkan permasalahan terletak pada kerning, mahasiswa tersebut akan membandingkan jarak antara huruf yang ada dalam desain hingga akhirnya mengetahui masalah jarak antara huruf mana yang dimaksud secara spesifik.

\section{makan apa nih sekarang?}

\section{Gambar 3 Ilustrasi Ruang dan Area dari Kerning, Word Spacing, Tracking dan Leading.}

(Sumber: Hananto, 2018)

Selain membahas mengenai jarak dalam mengejar balance, terdapat dua aspek lagi yang dituntut para mahasiswa dalam desain mereka, yaitu mengenai legibility dan readability. Legibility adalah tingkat perbedaan antara sebuah huruf dengan huruf lain, sedangkan readability adalah kemampuan agar sebuah kata atau kalimat dapat dibaca (Jury, 2006:82). Hal ini menunjukkan dua perbedaan signifikan, dimana lebility adalah aspek yang krusial ketika merancang sebuah huruf, sedangkan readability adalah aspek yang krusial untuk seorang desainer atau tipografer dalam membuat desain yang berisi tulisan. Walaupun demikian, bukan berarti seorang desainer tidak perlu mempedulikan lebility dari sebuah typeface; justru karena desainer harus memilih sebuah typeface dari sekian banyaknya typeface, maka harus memperhatikan secara seksama mengenai huruf yang digunakan, apakah ada masalah legibility atau tidak. Hal inilah yang menjadi aspek lain yang perlu dijawab oleh mahasiswa dalam latihan mendesain logotype ini. Apakah ada huruf-huruf yang memiliki bentuk ambigu, jika iya, mungkin perlu ada penyesuaian-penyesuaian tertentu; atau apakah eksplorasi sang mahasiswa untuk membuat desain tersebut unik malah 'mengorbankan' aspek keterbacaan? Isu-isu tersebut yang diperkenalkan dan dilatih dalam latihan ini.

\section{ANALISA HASIL}

Dalam latihan mendesain logotype ini, mahasiswa hanya diperbolehkan menggunakan satu dari sembilan typeface: Centaur, Garamond, Baskerville, Didot, Clarendon, Akzindenz Grotesk, Optima, Futura \& Helvetica. Sembilan typeface tersebut merupakan perwakilan dari Sembilan klasifikasi typeface yang digunakan dalam perkuliahan DKV UPH. Limitasi typeface ini didasari dari pemahaman bahwa lebih baik mahasiswa mengenal sembilan klasifikasi tersebut daripada mengetahui banyak jenis typeface namun tidak bisa membedakan atau menggunakannya dengan proporsional. Aturan tekhnis lain yang cukup krusial dalam latihan ini adalah penggunaan case yang bebas dan limitasi penggunaan warna, yaitu hanya boleh warna hitam (dan putih sebagai latar). Kedua hal tersebut dilakukan karena latihan ini ingin melihat kemampuan mahasiswa menguasai jarak untuk menciptakan keseimbangan visual). Batasan-batasan ini dilakukan dengan harapan mahasiswa dapat fokus kepada eksplorasi hal-hal yang berhubungan dengan tipografi, seperti pemilihan huruf, pengaturan tracking, kerning, word spacing atau leading, dan 
bukan pada komponen visual lain yang menjadi fokus dalam mata kuliah lain, seperti ilustrasi dan juga warna.

\section{1}

Gambar 4 Logotype 'monet' karya Adrian Owen

(Sumber: Hananto, 2018)

Gambar 4 adalah sampel logotype pertama, karya Adrian Owen yang menggunakan nama desainer 'Monet'. Typeface yang digunakan dalam logotype ini adalah Didone. Dengan menghilangkan beberapa bagian huruf secara konsisten, Adrian mampu menyeragamkan sekaligus menyederhanakan bentuk-bentuk huruf yang digunakan dalam logotype. Adrian juga membesarkan ukuran ' $t$ ' dan memotong bagian atas hurufnya sehingga secara visual huruf ' $\mathrm{t}$ ' yang hanya terdiri dari satu stem supaya secara visual dapat mengimbangi huruf-huruf lain yang memiliki dua atau tiga stem (' $m$ ', 'o', ' $n$ ', 'e'). Keputusan untuk menggunakan bentuk huruf ' $t$ ' seperti itu menghasilkan pengulangan bentuk stem yang dapat ditemukan di huruf ' $m$ ' dan ' $n$ ', sehingga menghasilkan repetisi bentuk yang membuat desain secara keseluruhan lebih menyatu.

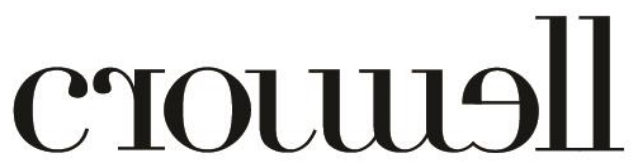

Gambar 5 Logotype 'crouwell' karya Hernandityo

(Sumber: Hananto, 2018)

Karya kedua, Gambar 5, adalah karya Logotype 'crouwell' karya Hernandityo. Nama desainer yang digunakan dalam desain ini adalah 'Crouwell'. Typeface yang digunakan oleh Hernandityo adalah Baskerville. Serupa dengan Adrian, Hernandityo memodifikasi bentuk huruf ' $u$ ' dengan cara memotong stem kanan dari huruf tersebut dan mendekatkannya dengan huruf ' $w$ '. Selain itu, Hernandityo juga membalikkan huruf ' $r$ ' dan 'e' untuk membentuk counter supaya terlihat lebih balance. Pengaturan tracking yang rapat ini menciptakan komposisi yang rapat, namun menciptakan bentuk visual yang baik antara ' $u$ ' dan ' $w$ ', serta menyatukan huruf ' $c$ ' dan ' $r$ ', ' $w$ ' dan 'e', serta ' 1 ' dan ' $l$ '.

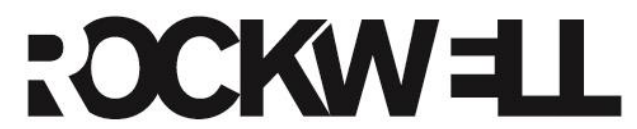

Gambar 6 Logotype 'crouwell' karya Karina Olivia

(Sumber: Hananto, 2018)

Logotype 'ROCKWELL' pada Gambar 6 adalah karya Karina Olivia. Nama yang digunakan oleh Karina adalah 'Rockwell' dan typeface yang digunakan adalah Akzidenz Grotesk. Karina menyusun hurufhuruf dalam 'rockwell; dengan tracking rapat sehingga banyak huruf yang saling menempel, seperti 'o' dan ' $c$ ', 'c' dan ' $k$ ', ' $k$ ' dan ' $w$ ', serta ' $l$ ' dan ' $l$ '. Karina juga mengubah ruang positif dan negatif pada huruf 'e' agar dapat menyatu dengan area negatif 'w' dan terlihat seimbang. Setelah itu, untuk membuat kesatuan secara visual, Karina juga menukar positif dan negatif dari huruf ' $r$ ' untuk mengimbangi huruf ' $e$ '.

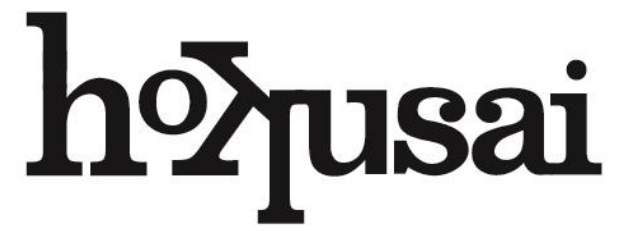

\section{Gambar 7 Logotype 'hokusai' karya Yehezkiel Penalosa (Sumber: Hananto, 2018)}

Hal paling menonjol dalam desain Yehezkiel (Gambar 7) adalah bentuk huruf ' $\mathrm{k}$ ' yang diputar dan dibalik. Desain yang menggunakan typeface Clarendon ini menggunakan nama 'hokusai' sebagai teks logotypenya. Perubahan huruf ' $\mathrm{k}$ ' tersebut menghadirkan stem pada area descender yang secara tidak langsung menyeimbangkan logotype yang awalnya memiliki dua stem pada area ascender (dari huruf ' $\mathrm{h}$ ' dan huruf ' $k$ '. untuk menyeimbangkan huruf 
' $\mathrm{k}$ ' tersebut, huruf 'o' juga dibuat lebih kecil dan lepas dari baseline untuk mengisi ruang kosong yang ada diantara huruf ' $\mathrm{k}$ ' dan ' $\mathrm{h}$ '. Perubahan terakhir yang cukup signifikan adalah dengan merubah terminal atas huruf 's' menyerupai terminal huruf ' $a$ ', sehingga keduanya menghasilkan bentuk yang unik dan memiliki counter yang seimbang.

\section{UaviU rgash}

Gambar 8 Logotype 'david carson' karya Juliana

(Sumber: Hananto, 2018)

Karya terakhir yang akan dibahas adalah karya Juliana yang menggunakan nama 'david carson'. Desain ini menggunakan typeface Baskerville. Juliana membagi tulisan 'david carson' kedalam dua baris dan memotong bagian-bagian huruf dalam tulisan tersebut. Menariknya, setiap huruf yang dipotong tersebut tetap legible, dan tulisan 'david carson' masih tetap terbaca dengan baik. Tindakan memotong tersebut juga menghilangkan area ascender yang dimiliki huruf 'd', yang memang membuat komposisi logotype sedikit tidak balance. Hal lain yang juga membuat desain ini menarik adalah proses penyatuan huruf ' $a$ ' dan ' $r$ ' yang menjadi sebuah ligatur. Selain untuk membuat bentuk yang menarik, ligatur tersebut juga memperkecil area teks sehingga secara keseluruhan baris pertama dan baris kedua tetap terlihat berimbang. Komponen terakhir yang juga membuat desain ini menarik adalah dengan menyisakan titik pada huruf ' $i$ '. Titik itu membantu menandakan bahwa huruf yang terpotong itu adalah huruf 'i', dan bukan huruf-huruf lain seperti ' $\mathrm{f}$ ' atau ' $\mathrm{l}$ '. Selain itu, titik yang diletakan itu juga secara visual memberi aksen dan mempertegas aksis yang muncul dari huruf 'i' dan 'o' yang sejajar (dibandingkan huruf-huruf lain dari kedua baris yang sama sekali tidak ada yang sejajar.

\section{PEMBAHASAN}

Kelima karya yang dibahas mungkin bukan karya-karya yang terbaik dari segi penilaian, namun kelima karya tersebut menjadi perwakilan dari desain-desain yang mencapai balance atau berusaha mencapai balance dengan pendekatan desain yang tepat. Artinya, eksplorasi dan modifikasi yang tampak pada logotype tersebut memiliki tujuan fungsional, yaitu untuk menciptakan balance, bukan hanya supaya unik ataupun supaya terlihat menarik. Dari pembahasan karya yang dilakukan, dapat dilihat bahwa solusi dalam mengejar balance ini dapat dilakukan dengan banyak cara, mulai dari memodifikasi anatomi huruf, merubah kondisi huruf (diputar atau dibalik), merubah posisi huruf terhadap keseluruhan teks (seperti huruf 'o' pada Gambar 7), dan sebagainya.

Mengenai latihan yang diberikan kepada mahasiswa dalam perkuliahan sendiri juga penulis rasa cukup berhasil mengingat hasil yang didapatkan cukup beragam. Pengembangan lebih lanjut mengenai latihan ini dapat dilakukan pada jenis typeface yang digunakan. Karena typeface yang berbeda tentu memiliki visual yang berbeda, maka kemungkinan untuk menemukan permasalahan desain yang berbeda walaupun menggunakan teks yang sama itu dapat terjadi. Beberapa kontrol dalam latihan ini juga dapat dilakukan secara metodologis, yaitu ketika mahasiswa dituntut untuk melakukan eksplorasi dengan jumlah dan pendekatan atau parameter tertentu.

Jika ingin lebih fokus dalam menilai solusi visual yang dapat dihasilkan, permasalahan visual yang diberikan kepada satu kelas juga dapat dibuat sama, sama-sama menggunakan teks dan typeface yang sama. Hasilnya tentu dapat dikomparasikan dengan lebih langsung dibandingkan apa yang telah dilakukan sekarang. 


\section{SIMPULAN}

Untuk menutup tulisan ini, penulis merasa bahwa dalam tipografi dewasa ini, masih banyak hal mendasar yang dapat dibahas dan dipelajari lebih lagi. Seperti halnya mengenai atribut keseimbangan, yang sebenarnya merupakan atribut primitif (mengingat balance merupakan sesuatu yang lekat dalam desain sejak dulu kala), namun penelitian dalam perkuliahan ini menunjukkan bahwa ada banyak cara untuk mendapatkan keseimbangan dengan permasalahan-permasalahan yang juga beragam. Dengan demikian disarankan untuk penelitian-penelitian ataupun publikasi yang sifatnya membahas sisi formalis dari sebuah desain sebagai referensi teori dan juga referensi metodologi.

\section{ACKNOWLEDGEMENTS}

Ucapan terima kasih disampaikan kepada pihak-pihak yang terlibat dalam publikasi ini: Ade Maradhona Shantio Wijaya, Alfiansyah Zulkarnain, Anastasia Callista, Christo Wahyudi, Ellis Melini, Ferra Deviana Halim, Irwan Harnoko, Nita Virena Nathania, Noor Wirama, Valerie Wirjaatmadja selaku tim dosen dalam mata kuliah Tipografi Dasar; Celine Wisuna, Eldad Timothy, Felicia Kristella, Felicia Violetta, Jeffry Immanuel, Kartika Magdalena, Livia Margarita, Shella Subagia sebagai asisten dosen yang membantu pelaksanaan kelas; Adrian Owen, Hernandityo, Juliana, Karina Olivia, Yehezkiel Penalosa yang karyanya digunakan sebagai sampel dalam tulisan ini.

\section{DAFTAR PUSTAKA}

Bringhurst, Robert. The Elements of Typographic Style. Ed. 3. Point Roberts: Hartley \& Marks, Publishers, 2004.

Jury, David. About Face : Reviving the Rules of Typography. Brighton : Rotovision, 2004.

Jury, David. What is Typography. Kaki Bukit : Rotovision, 2006.

Landa, Robin. Graphic Design Solutions. Boston: Wadsworth, 2011.

Lupton, Ellen. Thinking with Type : a Critical Guide for Designers, Writers, Editors \& Students. Ed. 1. New York : Princeton Architectural Press, 2004.

Solomon, Martin. The Art of Typography. Ed. 2. New York: Art Direction Book Company, 1994.

Sihombing, Danton. Tipografi Dalam Desain Grafis. Jakarta: Penerbit PT Gramedia Pustaka Utama, 2001. 